\title{
Mystery Case: Bilateral alopecia as clue to diagnosis of Gomez-Lopez-Hernandez syndrome in a 38-year-old man
}

Cornelius Kronlage, MD, and Daniel G. Healy, MD

Neurology ${ }^{\circledR}$ 2019;93:408-410. doi:10.1212/WNL.0000000000008004

Figure 1 Brain imaging findings in Gomez-Lopez-Hernandez syndrome (GLHS)
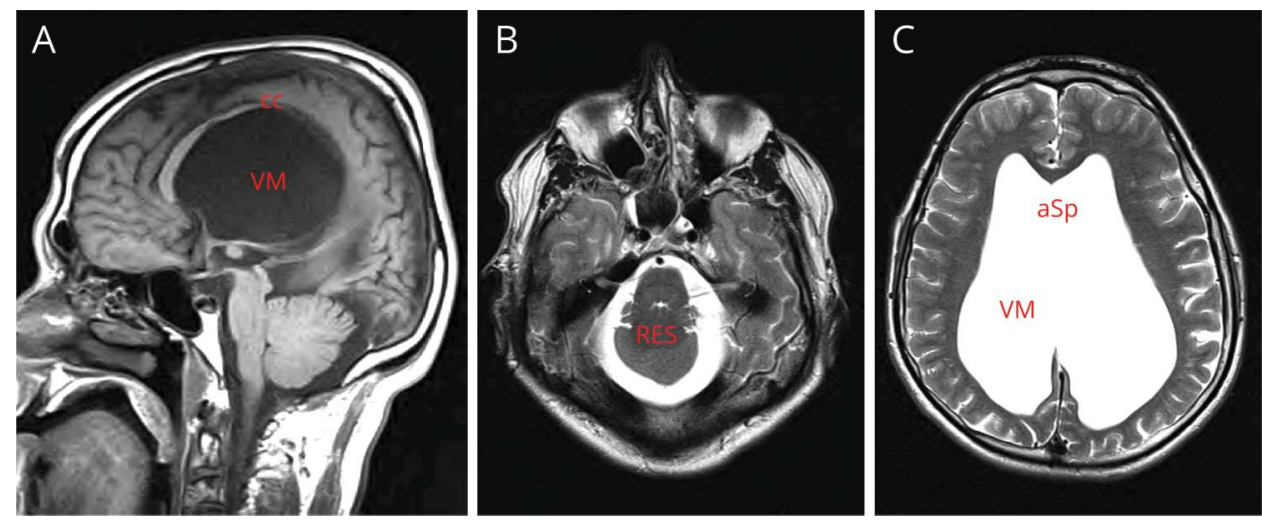

(A) Sagittal T1-weighted and (B, C) axial T2-weighted MRI show hypoplasia of brainstem and cerebellum with absence of the vermis_signifying rhombencephalosynapsis (RES) —and marked ventriculomegaly (VM). Other findings common in GLHS include absent septum pellucidum (aSp) and dysplastic corpus callosum (cc).

A 38-year-old man with a diagnosis of cerebral palsy had MRI for headache. This showed hydrocephalus with aqueductal stenosis and a hypoplastic cerebellum (figure 1). On detailed examination, bilateral triangular patches of alopecia (figure 2) stood out. Subsequently, absent corneal reflexes were found, while careful review of the imaging revealed rhombencephalosynapsis (RES).

The triad of alopecia, trigeminal anesthesia, and RES defines Gomez-Lopez-Hernandez syndrome (GLHS), a rare congenital malformation syndrome of unknown etiology. GLHS is part of a spectrum of RES-associated malformations ${ }^{1}$ that may account for as many as $9 \%$ of congenital aqueductal stenoses. ${ }^{2}$

Hair abnormalities are also distinctive in other rare neurologic diagnoses, for example, cerebral autosomal recessive arteriopathy with subcortical infarcts and leukoencephalopathy (CARASIL) (premature alopecia), Menkes syndrome (curly, brittle hair; pili torti), WoodhouseSakati syndrome (premature, progressive alopecia), and giant axonal neuropathy (curly, "kinky" hair).

\section{Author contributions}

C. Kronlage assisted in the patient's clinical assessment, drafted and revised the manuscript, and created the figures. D. G. Healy performed the patient's clinical assessment and revised the manuscript and figures.

\section{Correspondence}

Dr. Kronlage

cornelius.kronlage@usb.ch

MORE ONLINE

Survey and results

NPub.org/mc9309 

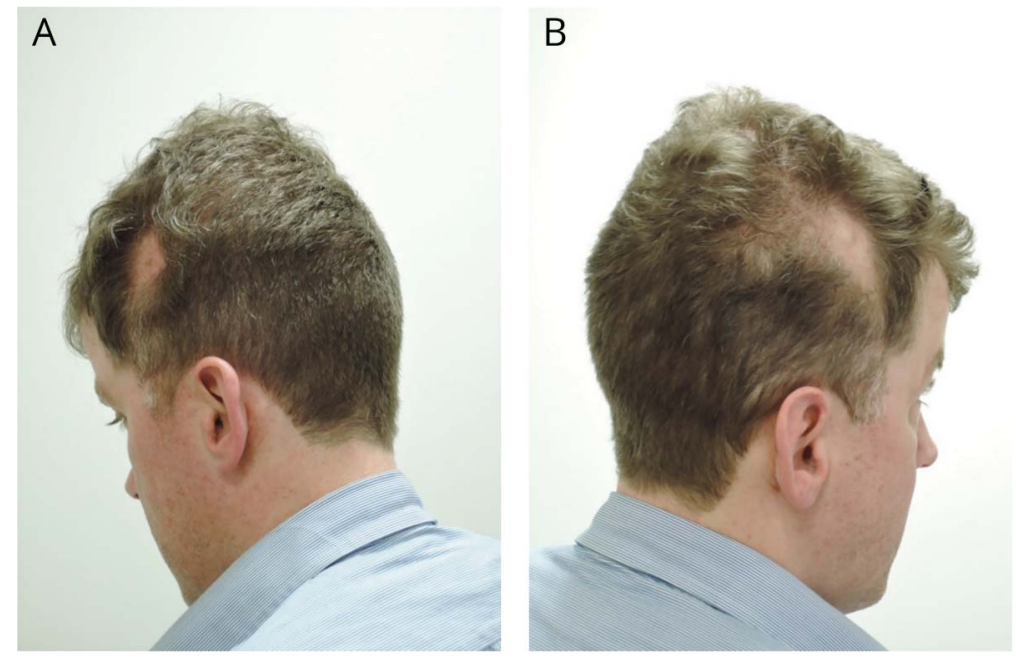

(A, B) Bilateral triangular alopecia on the parieto-occipital scalp.

\section{Acknowledgment}

The authors thank the patient for permission to publish this report and his family for support in its preparation.

\section{Study funding}

Not targeted funding reported.

\section{Disclosure}

The authors report no disclosures relevant to the manuscript. Go to Neurology.org/N for full disclosures.

\section{References}

1. Tully HM, Dempsey JC, Ishak GE, et al. Beyond Gómez-López-Hernández syndrome: recurring phenotypic themes in rhombencephalosynapsis. Am J Med Genet A 2012;158A:2393-2406.

2. Ishak GE, Dempsey JC, Shaw DWW, et al. Rhombencephalosynapsis: a hindbrain malformation associated with incomplete separation of midbrain and forebrain, hydrocephalus and a broad spectrum of severity. Brain 2012;135:1370-1386.

\section{Mystery Case Responses}

The Mystery Case series was initiated by the Neurology ${ }^{\circledR}$ Resident \& Fellow Section to develop the clinical reasoning skills of trainees. Residency programs, medical student preceptors, and individuals were invited to use this Mystery Case as an educational tool. Responses to multiple choice questions formulated using this case were solicited through a group email sent to the American Academy of Neurology Consortium of Neurology Residents and Fellows and through social media. We received 129 responses. The majority of respondents (73\%) had been in practice for $1-4$ years; $68 \%$ were residents or fellows while $23 \%$ were faculty/boardcertified physicians; the remainder were medical students or advanced practice providers. $65 \%$ resided outside the United States. A wide range of practice settings were represented.

The 38-year-old patient with a historic diagnosis of cerebral palsy underwent an MRI brain for investigation of headache.
On reviewing the imaging, most respondents correctly identified hypoplasia of the cerebellar vermis and corpus callosum (63\%) and ventriculomegaly (78\%). However, only 36\% identified brainstem hypoplasia. The most common incorrect answer was hydrancephaly (24\%), a congenital brain defect in which the cerebral hemispheres are replaced by fluid-filled cavities, usually presenting in infancy with macrocephaly. ${ }^{1}$

Of the listed neurologic conditions, GLHS (40\%), VogtKoyanagi-Harada syndrome (28\%), and CARASIL (19\%) were correctly identified as being associated with alopecia. The most common incorrect answers were zinc toxicity (44\%; zinc deficiency can cause alopecia), phenytoin use (36\%; associated with hirsutism), and Menkes syndrome (33\%; a congenital X-linked disorder causing copper deficiency and associated with "kinky" hair ${ }^{2}$ ).

GLHS was correctly identified as being the triad of alopecia, trigeminal anesthesia, and RES by most respondents (53\%). RES is the term given to the congenital cerebellar abnormalities seen in GLHS and other disorders, which are associated with cerebellar signs, cerebral palsy, and intellectual developmental delay. ${ }^{3}$ The most common incorrect answer was Vogt-Koyanagi-Harada syndrome (12\%), a multisystem disease caused by melanocyte inflammation and more common in darker skinned ethnicities. Features include chronic panuveitis, vitiligo, alopecia, dysacousia, meningeal irritation, and poliosis. ${ }^{4}$

This case highlights the characteristic features of a rare syndrome, recognition of which offers some diagnostic specificity for those labeled as having "cerebral palsy." Several neurologic disorders are associated with skin and hair abnormalities, and their appreciation can narrow differential diagnoses and aid identification of treatable causes. 
Robert Hurford, MSc, MRCP (UK)

Nuffield Department of Clinical Neurosciences, University of Oxford

\section{References}

1. NORD: National Organization for Rare Disorders. Hydranencephaly. 2007. Available at: rarediseases.org/rare-disease-information/rare-diseases/byID/369/viewFullReport. Accessed June 2019.
2. de Bie P, Muller P, Wijmenga C, Klomp LW. Molecular pathogenesis of Wilson and Menkes disease: correlation of mutations with molecular defects and disease phenotypes. J Med Genet 2007;44:673.

3. Toelle SP, Yalcinkaya C, Kocer N, et al. Rhombencephalosynapsis: clinical findings and neuroimaging in 9 children. Neuropediatrics 2002;33:209-214.

4. GARD: Genetic and Rare Diseases Information Center. Vogt-Koyanagi-Harada disease. Available at: rarediseases.info.nih.gov/diseases/7862/vogt-koyanagi-haradadisease. June 2019

\section{Quality Improvement: Start Small to Make Big Changes}

You deliver excellent patient care, but there is always room for improvement. In health care, quality improvement (QI) is the framework used to systematically improve the ways care is delivered to patients. Learn how to increase desired health outcomes. Browse AAN resources to help you drive change at AAN.com/view/QI.

\section{Visit the Neurology ${ }^{\circledR}$ Website at Neurology.org/N}

- More article-based content on home pages

- Streamlined menus and navigation

- Enhanced blog sections for specialty areas

- Same experience on desktop, tablet, and mobile devices

- Audio summaries of current issues

- Improved article reading experience; links more evident (pdf, analytics, social media)

- Neurology ${ }^{\circledR}$ Clinical Practice initiative "Practice Current" global surveys will be accessible across sites

f Find Neurology ${ }^{\circledR}$ on Facebook: http://tinyurl.com/neurologyfan

Follow Neurology ${ }^{\circledR}$ on Twitter: https://twitter.com/GreenJournal

\section{Disputes \& Debates: Rapid online correspondence}

The editors encourage comments on recent articles through Disputes \& Debates:

Access an article at Neurology.org/ $\mathrm{N}$ and click on "COMMENT" beneath the article header. Responses will be posted within 3 business days.

Before submitting a comment to Disputes \& Debates, remember the following:

- Disputes \& Debates is restricted to comments about studies published in Neurology within the last eight weeks

- $\quad$ Read previously posted comments; redundant comments will not be posted

- Your submission must be 200 words or less and have a maximum of five references; reference one must be the article on which you are commenting

- You can include a maximum of five authors (including yourself) 


\section{Neurology}

\section{Mystery Case: Bilateral alopecia as clue to diagnosis of Gomez-Lopez-Hernandez syndrome in a 38-year-old man \\ Cornelius Kronlage and Daniel G. Healy \\ Neurology 2019;93;408-410 \\ DOI 10.1212/WNL.0000000000008004}

\section{This information is current as of August 26, 2019}

\section{Updated Information \& Services}

References

Subspecialty Collections

Permissions \& Licensing

Reprints including high resolution figures, can be found at: http://n.neurology.org/content/93/9/408.full

This article cites 4 articles, 1 of which you can access for free at: http://n.neurology.org/content/93/9/408.full\#ref-list-1

This article, along with others on similar topics, appears in the following collection(s):

\section{Cerebellum}

http://n.neurology.org/cgi/collection/cerebellum

Clinical neurology examination

http://n.neurology.org/cgi/collection/clinical_neurology_examination MRI

http://n.neurology.org/cgi/collection/mri

Other neurocutaneous disorders

http://n.neurology.org/cgi/collection/other_neurocutaneous_disorders

Information about reproducing this article in parts (figures,tables) or in its entirety can be found online at:

http://www.neurology.org/about/about_the_journal\#permissions

Information about ordering reprints can be found online:

http://n.neurology.org/subscribers/advertise

Neurology ${ }^{\circledR}$ is the official journal of the American Academy of Neurology. Published continuously since 1951, it is now a weekly with 48 issues per year. Copyright @ 2019 American Academy of Neurology. All rights reserved. Print ISSN: 0028-3878. Online ISSN: 1526-632X.

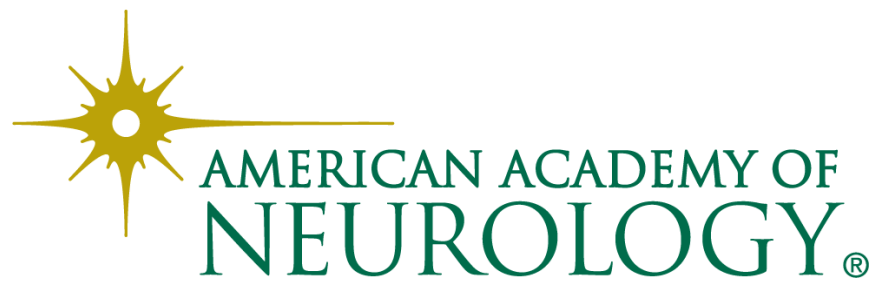

